\title{
Birth Defects at the Outpatient Department of the Philippine General Hospital from 2000-2010
}

\author{
Carmencita D. Padilla, ${ }^{1,2}$ Melissa Mae P. Baluyot, ${ }^{2}$ Aster Lynn D. Sur, ${ }^{2}$ \\ Roxanne Janica E. Merencilla ${ }^{2}$ and Maria Melanie Liberty B. Alcausin ${ }^{1,2}$ \\ ${ }^{1}$ Department of Pediatrics, College of Medicine and Philippine General Hospital, University of the Philippines Manila \\ 2Institute of Human Genetics, National Institutes of Health, University of the Philippines Manila
}

\begin{abstract}
Introduction. Birth defects or congenital anomalies are a major global concern. An estimated 7.9 million children are born worldwide each year. Birth defects are among the top ten leading causes of infant deaths in the Philippines for more than six decades. The objectives of this study were to: 1) determine the frequency of birth defects among patients seen at the Outpatient Department (OPD) of the Philippine General Hospital (PGH) from 2000 to 2010; 2) describe the birth defects by organ systems and presentation (isolated, part of a recognizable syndrome, chromosomal syndrome or multimalformed case); 3) present the distribution of patients by geographic origin; 4) describe the birth defects according to age group and organ system; and 5) compare the data from this study to the previously published report among admitted patients at PGH in the same time period.
\end{abstract}

Methods. Medical records of new patients seen at the PGH OPD from 2000 to 2010 were reviewed. Medical records that included written diagnosis of any of the following International Classification of Diseases (ICD) -10 codes (Q $00-Q$ 99, P 35.0, P 83.5, K40, H49.0, H50.0, H50.1, H53.0, H54.42, H54.7, and H55.01) were considered birth defect cases.

Results. Out of the 804,410 new patients at the PGH OPD from 2000 to $2010,12,827$ patients (1.59\%) had a diagnosis of at least one major structural birth defect. The most common birth defects were cardiovascular, digestive, genital organ and nervous system anomalies. The top 5 anomalies in this report were: congenital malformations of cardiac septa, other congenital malformations not elsewhere classified, cleft palate with cleft lip, congenital hydrocoele, and congenital hydrocephalus. The highest percentage of birth defects were from the $<1$ age group (40.3\%), followed by the 1 to 4 age group (29\%) and the 5 to 9 age group (14.6\%). NCR, Region IV-A and Region III had the highest percentages of patients with birth defects, $51.4 \%, 26.03 \%$ and $10.97 \%$, respectively.

Conclusion. This study revealed a prevalence of birth defects among PGH OPD patients of $1.59 \%$. The most common birth

Corresponding author: Carmencita D. Padilla, MD, MAHPS

Department of Pediatrics

Philippine General Hospital

University of the Philippines Manila

Taft Avenue, Ermita, Manila 1000 Philippines

Telephone: +632 5268419

Email: cdpadilla@up.edu.ph defects were possibly surgically correctable reflecting the nature of PGH as a referral center. Majority of patients affected were in the under- 5 population. The study reflects the importance of a birth defects surveillance to develop policies on strategies that will reduce the burden of morbidity and mortality secondary to preventable birth defects like congenital rubella syndrome that can be aborted by a successful immunization program. The birth defects surveillance will generate data that will support strengthening the regional hospitals with a better complement of specialists and capability for both medical and surgical management of the patients.

Key Words: birth defects, congenital anomalies, congenital abnormalities, Philippine General Hospital

\section{Introduction}

Birth defects or congenital anomalies continue to be a major global concern. Serious birth defects of genetic or partially genetic origin are born to an estimated 7.9 million children or six percent of total births every year. Serious birth defects can be lethal and for those who survive, these disorders can cause lifelong disability. There are also hundreds of thousands more who are born with serious birth defects of post-conception origin, including maternal exposure to environmental agents (teratogens) such as alcohol, rubella, syphilis and iodine deficiency that can harm a developing fetus. The March of Dimes Global Report on Birth Defects revealed that at least 3.3 million children under five years of age die from birth defects each year and an estimated 3.2 million of those who survive may be disabled for life. ${ }^{1}$

In the Philippines, congenital anomalies have been consistently in the top ten causes of infant mortality for the past six decades. ${ }^{2}$ To influence policy development for surveillance of birth defects, there have been several efforts to gather local data., ${ }^{3,4}$ The retrospective study involving patients admitted at the PGH from 2001-2010 revealed a birth defect prevalence of $2 \%$ across all age groups. ${ }^{4}$

A birth defect is defined as any abnormality affecting body structure or function that is present from birth. It may be clinically obvious at birth or may be diagnosed only later in life. ${ }^{1}$ Synonymous terms that are often used are 'congenital anomalies,' 'congenital abnormalities' and 'congenital malformations'. ${ }^{5}$ There are two main categories of birth defects: structural birth defects and functional, or 
developmental birth defects. Structural birth defects are related to a problem with body parts and structure. Functional or developmental birth defects are related to a problem with how a body part or body system works. These problems often lead to intellectual and developmental disability and can include nervous system or brain problems, sensory problems, metabolic disorders, and degenerative disorders. ${ }^{6}$

Birth defects can be single (isolated or sequence) or multiple (associated defect in multimalformed case, part of recognizable syndrome, and chromosomal syndrome). Sequence refers to anomalies due to a single problem in morphogenesis that leads to a cascade of subsequent effects (e.g. amnion rupture sequence). ${ }^{7}$ Multiple structural defects that occur due to a single inciting event are called malformation syndromes. ${ }^{7}$ Those that are due to a chromosomal problem are called chromosomal syndromes. Those that have been described in literature have been classified as 'part of a recognizable syndrome.' Those that are labelled 'multiple congenital anomalies' with no specific syndrome have been classified 'associated defect in multimalformed case.'

There are major and minor anomalies. Major structural anomalies are defined as structural changes that have significant medical, social or cosmetic consequences, and typically require medical intervention. Examples include cleft lip and spina bifida. In contrast, minor congenital anomalies are structural changes that pose no significant health problem in the neonatal period and tend to have limited social or cosmetic consequences for the affected individual. ${ }^{5}$ Examples include ear tags, high arched palate and clinodactyly.

The objectives of the study were to 1 ) determine the percentage of patients with birth defects at the PGH OPD; 2) describe the birth defects by organ systems and presentation (isolated, part of a recognizable syndrome, chromosomal syndrome or multi-malformed case); 3) present the distribution of patients by geographic origin; 4) describe the birth defects according to age group and organ system; and 5) compare the data from this study to the previously published report among admitted patients at PGH in the same time period.

\section{Methods}

\section{Study Setting}

The PGH has a 1,500-bed capacity with an average of 600,000 patients seen annually for both inpatients and outpatients. It is state-owned, administered and operated by the University of the Philippines Manila. The OPD houses clinics of the following 12 specialty services: Family Medicine, Internal Medicine, Neurosciences, Dermatology, Allergy and Immunology, Obstetrics and Gynecology, Ophthalmology, Orthopedics, Otorhinolaryngology-Head and Neck Surgery, Pediatrics, Psychiatry, Rehabilitation Medicine and Surgery. Other services/clinics at the OPD are Traditional Medicine, Nutrition Clinic, Anti-Rabies Unit, and Dentistry. Being a tertiary referral center, it receives patient referrals needing specialized medical care and intervention from other healthcare institutions all over the country.

\section{Inclusion Criteria and Exclusion Criteria}

Only new patients seen at the PGH OPD from 2000 to 2010 were included in the study. Medical records of outpatients were kept at the Main Medical Records Section and at the Cancer Institute. Only the medical records of outpatients at the Main Medical Records Section were included in this study. Medical records that included written diagnosis of any of the following ICD-10 codes (Q00 - Q99, P35.0, P83.5, K40, H49.0, H50.0, H50.1, H53.0, H54.42, H54.7, and H55.01) were considered birth defect cases. These codes correspond to congenital anomalies and syndrome diagnoses: specifically, Q00 - Q99 represent congenital malformations, deformations and chromosomal abnormalities, P35.0 congenital rubella syndrome, P83.5 congenital hydrocele, K40 inguinal hernia, H49.0 third oculomotor nerve palsy, H50.0 esotropia, H50.1 exotropia, H53.0 amblyopia ex anopsia, H54.42 blindness, left eye, normal vision right eye, H54.7 unspecified visual loss, and H55.01 congenital nystagmus.

In this study, birth defects referred to structural anomalies and not functional ones.

The following were excluded: 1) patients who were reported to have minor birth defects (Appendix A); 2) patients with metabolic disorders and functional problems; and 3) patients who have been initially identified as having birth defects but did not have final or definitive diagnoses such as patients with records containing the following words in the diagnosis: to consider, versus, probably and without supporting laboratory or ancillary procedures.

Birth defects were counted separately such as a patient may have more than one birth defect. Accordingly, the total number of birth defects were more than the total number of patients.

\section{Data Collection}

Medical records of all new patients seen at the PGH OPD meeting the inclusion criteria from 2000 to 2010 were retrieved and reviewed. This was done after securing approval from the institution's Ethics Review Board. The following data from the medical records were then encoded into a secure password-protected database: demographic information [name, case number, gender, date of birth, nationality, province of origin, plurality (singleton or twin etc.), parents' identifying data (name, age and occupation)], prenatal data (maternal illness and medications taken during pregnancy), family history, specific diagnoses, and 
laboratory work-up. The written diagnoses and ICD-10 codes of the cases were then verified by the genetics fellows and consultants, and recorded.

\section{Data Analysis}

Of the total number of new patients seen at the OPD between the years 2000-2010, the frequency of birth defects was reported per 10,000 patients. The number of birth defects was also reported per year. The frequency of birth defects according to type was also reported and the top 10 birth defects were identified.

\section{Results}

From 2000 to 2010, there were 822,494 outpatients at the PGH. Of the 822,494 outpatients, there were 804,410 charts available at the Main Medical Records Section for review. Medical records at the Cancer Institute were not reviewed.

Out of the 804,410 new patients who consulted at the PGH OPD from 2000 to 2010, 12,827 patients (1.59\%) had a diagnosis of at least one major structural birth defect (Table 1).

Table 1. Annual Number of Patients Seen, Birth Defects Cases and Prevalence at the Outpatient Department of the Philippine General Hospital from 2000 to 2010

\begin{tabular}{cccc}
\hline Year & $\begin{array}{c}\text { Total Number of } \\
\text { New OPD } \\
\text { Patients }\end{array}$ & $\begin{array}{c}\text { Total Number of } \\
\text { OPD Patients with } \\
\text { Birth Defects }\end{array}$ & $\begin{array}{c}\text { Patients with Birth } \\
\text { Defects Per 10,000 } \\
\text { OPD Patients }\end{array}$ \\
\hline $\mathbf{2 0 0 0}$ & 91,889 & 1,300 & 141.5 \\
$\mathbf{2 0 0 1}$ & 83,442 & 1,845 & 221.1 \\
$\mathbf{2 0 0 2}$ & 79,706 & 1,335 & 167.5 \\
$\mathbf{2 0 0 3}$ & 74,232 & 1,545 & 208.1 \\
$\mathbf{2 0 0 4}$ & 73,202 & 1,513 & 206.7 \\
$\mathbf{2 0 0 5}$ & 74,340 & 1,452 & 195.3 \\
$\mathbf{2 0 0 6}$ & 74,939 & 914 & 121.9 \\
$\mathbf{2 0 0 7}$ & 66,980 & 949 & 141.7 \\
$\mathbf{2 0 0 8}$ & 66,033 & 470 & 71.2 \\
$\mathbf{2 0 0 9}$ & 62,643 & 758 & 121.0 \\
$\mathbf{2 0 1 0}$ & 57,004 & 746 & 130.9 \\
TOTAL & $\mathbf{8 0 4 , 4 1 0}$ & $\mathbf{1 2 , 8 2 7}$ & $\mathbf{1 5 9 . 5}$ \\
\hline
\end{tabular}

* Cancer and Breast Clinic were excluded

* Included clinics were: Allergy, Dental, Dermatology, Family Medicine, General Surgery, Internal Medicine, Nutrition Clinic, Neurology, OB-Gyne, Orthopedics, Otorhinolaryngology, Pediatrics, Psychiatry, Rehabilitation Medicine, Traditional Medicine, Anti-Rabies Unit
Table 2 shows the top 10 birth defects at the PGH OPD. Three out of the top 10 birth defects were digestive system anomalies - combined cleft palate and cleft lip, isolated cleft palate and congenital absence, atresia and stenosis of the large intestine.

Among the 12,827 patients with birth defects, majority were isolated defects seen in $83 \%$ of the cases, $9.1 \%$ were associated defects in multimalformed cases, $1.8 \%$ with defects that are part of a recognizable syndrome, and $6.1 \%$ with defects that are part of chromosomal syndromes (Table 3 ).

Table 3 also shows that out of the 16, 316 birth defects (some patients had multiple defects), 20.4\% were cardiovascular system anomalies, 20.3\% were digestive system anomalies, $16.6 \%$ were genital organ anomalies and $11.5 \%$ were nervous system anomalies (see Appendix B for the complete list of birth defects and their respective ICD-10 codes).

Cardiovascular system anomalies (41.36 per 10,000 patients) and digestive system anomalies (41.14 per 10,000 patients) were the most prevalent birth defects in this study. This was followed by genital organ anomalies (33.61 per 10,000 patients) and nervous system anomalies (23.31 per 10,000 patients).

Among the 3,327 cardiovascular system anomalies, the majority were isolated at $60.4 \%$ (2,010 out of 3,327). Most were malformations of the cardiac septa $(1,975$ out of 3,327 , $59.4 \%$ ) which included ventricular septal defect and atrial septal defect, followed by malformations of the great arteries (814 out of $3,327,24.5 \%)$ in the form of patent ductus arteriosus. For the digestive system anomalies, combined cleft lip and palate $(1,153$ out of $3,309,34.8 \%)$ topped the list, followed by isolated cleft palate (605 out of 3,309, 18.3\%), congenital absence, atresia and stenosis of small intestine (496 out of 3,309, 15\%), and isolated cleft lip (433 out of $3,309,13.1 \%)$. For genital organ anomalies, most of the defects identified were hydrocele (1,082 out of 2,704, $40 \%)$, undescended testicle (775 out of 2,704, 28.7\%) and hypospadias (381 out of 2,704, 14.1\%). For nervous system anomalies, the most common reported defect was congenital hydrocephalus (816 out of 1,875, 43.5\%). There were no reported anencephaly cases in this study.

\begin{tabular}{|c|c|c|c|c|c|c|c|c|}
\hline $\begin{array}{l}\text { Rank in } \\
\text { Frequency }\end{array}$ & $\begin{array}{l}\text { ICD } \\
\text { Code }\end{array}$ & Diagnosis & $\begin{array}{c}\text { Isolated } \\
\text { and } \\
\text { Sequence }\end{array}$ & $\begin{array}{c}\text { Associated } \\
\text { defect } \\
\text { in MMC }\end{array}$ & $\begin{array}{c}\text { Part of } \\
\text { recognizable } \\
\text { syndrome }\end{array}$ & $\begin{array}{c}\text { Part of } \\
\text { chromosomal } \\
\text { syndromes }\end{array}$ & Total & $\begin{array}{c}\text { Occurrence } \\
\text { per } 10,000 \\
\text { OPD patients }\end{array}$ \\
\hline 1 & Q21 & Congenital malformations of cardiac septa & 1,324 & 447 & 28 & 176 & 1,975 & 24.55 \\
\hline 2 & Q89 & Other congenital malformations, not elsewhere classified & 157 & 1181 & 2 & 0 & 1,340 & 16.66 \\
\hline 3 & Q37 & Cleft palate with cleft lip & 1,036 & 111 & 1 & 5 & 1,153 & 14.33 \\
\hline 4 & P83.5 & Congenital hydrocoele & 1,074 & 8 & 0 & 0 & 1,082 & 13.45 \\
\hline 5 & Q03 & Congenital hydrocephalus & 741 & 70 & 3 & 2 & 816 & 10.14 \\
\hline 6 & Q25 & Congenital malformations of great arteries & 443 & 263 & 40 & 68 & 814 & 10.12 \\
\hline 7 & Q53 & Undescended testicle & 630 & 126 & 3 & 16 & 775 & 9.63 \\
\hline 8 & Q90 & Down syndrome & 0 & 0 & 0 & 758 & 758 & 9.42 \\
\hline 9 & Q35 & Cleft palate & 507 & 84 & 7 & 7 & 605 & 7.52 \\
\hline 10 & Q42 & Congenital absence, atresia and stenosis of large intestine & 385 & 61 & 4 & 46 & 496 & 6.17 \\
\hline
\end{tabular}


Table 3. Frequency of Isolated Defects, Associated Defects in Multimalformed Cases (MMC), Defects as Part of Recognizable Syndromes, and Defects as Part of Chromosomal Syndromes by ICD-10 Classification among Patients seen at the Outpatient Department of the Philippine General Hospital from 2000-2010

\begin{tabular}{|c|c|c|c|c|c|c|}
\hline Organ system & $\begin{array}{l}\text { Isolated } \\
\text { And } \\
\text { Sequence }\end{array}$ & $\begin{array}{c}\text { Associated } \\
\text { defect } \\
\text { in MMC }\end{array}$ & $\begin{array}{c}\text { Part of } \\
\text { Recognizable } \\
\text { syndrome }\end{array}$ & $\begin{array}{c}\text { Part of } \\
\text { Chromosomal } \\
\text { syndromes }\end{array}$ & $\begin{array}{c}\text { Total } \\
\text { (\% of total } \\
\text { defects) }\end{array}$ & $\begin{array}{c}\text { Occurrence } \\
\text { per } 10,000 \\
\text { patients }\end{array}$ \\
\hline Nervous system & 1,564 & 283 & 19 & 9 & $1,875(11.5 \%)$ & 23.31 \\
\hline Eye Anomalies & 597 & 207 & 73 & 20 & $897(5.5 \%)$ & 11.15 \\
\hline Ear Anomalies, Face and Neck & 357 & 87 & 34 & 7 & $485(3 \%)$ & 6.03 \\
\hline Cardiovascular System Anomalies & 2,010 & 985 & 82 & 250 & $3,327(20.4 \%)$ & 41.36 \\
\hline Respiratory System Anomalies & 40 & 13 & 1 & 1 & $55(0.3 \%)$ & 0.68 \\
\hline Digestive System Anomalies & 2,887 & 336 & 19 & 67 & $3,309(20.3 \%)$ & 41.14 \\
\hline Genital Organ Anomalies & 2,377 & 290 & 8 & 29 & $2,704(16.6 \%)$ & 33.61 \\
\hline Urinary System Anomalies & 32 & 18 & 4 & 2 & $56(0.3 \%)$ & 0.70 \\
\hline Musculoskeletal System Anomalies & 595 & 553 & 60 & 35 & $1,243(7.6 \%)$ & 15.45 \\
\hline Chromosomal abnormalities & 0 & 0 & 0 & 783 & $783(4.8 \%)$ & 9.73 \\
\hline Others & 182 & 1,196 & 201 & 3 & $1,582(9.7 \%)$ & 19.67 \\
\hline Total Number of Birth Defects & $10,641(65.2 \%)$ & $3,968(24.3 \%)$ & $501(3.1 \%)$ & $1,206(7.4 \%)$ & 16316 & \\
\hline Total Number of Patients & $10,641(83 \%)$ & $1,172(9.1 \%)$ & $231(1.8 \%)$ & $783(6.1 \%)$ & 12827 & \\
\hline
\end{tabular}

There were 231 patients with recognizable syndromes comprising $1.8 \%$ of all patients included in the study. The most common was congenital rubella syndrome (110 cases, 1.37 per 10,000 patients). Table 3 shows that several organ systems were affected among the recognizable syndromes and the top 3 were cardiovascular system, eye anomalies and musculoskeletal system.

There were 783 cases of chromosomal syndromes comprising $6.1 \%$ of all patients included in the study. Down syndrome was the most common chromosomal abnormality (96.8\%). Cardiovascular system anomalies and digestive system anomalies were often seen in patients with chromosomal syndromes.

Among the 10,641 recorded isolated defects, digestive and genital organ anomalies made up approximately half of the cases. On the other hand, cardiovascular system anomalies and musculoskeletal system anomalies were the common defects that were associated as part of multimalformed cases.

As shown in Figures 1 and 2, out of the 12,827 patients with birth defects, $94.7 \%$ were from Luzon with majority from NCR (51.41\%) and IV-A CALABARZON (26.03\%). The hospital also received referrals from the Visayas $(2.5 \%)$ and Mindanao (1\%).

Table 4 shows the breakdown of patients with birth defects according to place of residence, and the percentage of patients of birth defects among the total number of patients with birth defects.

Table 5 shows the distribution of birth defect cases categorized by age group and organ system. The age groups were divided into 5-year categories. The highest percentage of birth defects were from the $<1$ age group $(40.3 \%)$, followed by the 1 to 4 age group (29\%) and the 5 to 9 age group $(14.6 \%)$. In the $<1$ age group, the most common isolated defects were digestive system anomalies $(28.47 \%)$, nervous system anomalies (18.82\%) and cardiovascular system anomalies (13.53\%). Chromosomal abnormalities $(6.6 \%)$ and multiple congenital anomalies (11.83\%) occurred mostly in the $<1$ age group. In younger age groups up to the 25 to 34 age group, genital organ, cardiovascular system anomalies, and digestive system anomalies were in the top three, with slight differences in order/rank. In the 35 to 44 and $>44$ age groups, the top three birth defects included genital organ anomalies (most common for both), cardiovascular system anomalies and other anomalies.

It was observed that there has been a decline in the number of patients consulting at the PGH OPD from 2000 to 2010. A similar observation was noted in the retrospective study for PGH inpatients from 2001-20104 (Figure 3).

Table 4. Number and percentage of patients with birth defects according to place of regional residence of outpatients at PGH

\begin{tabular}{lrc}
\hline \multicolumn{1}{c}{$\begin{array}{c}\text { Regional Residence } \\
\text { of patients }\end{array}$} & $\begin{array}{c}\text { Number of } \\
\text { Patients } \\
\text { with Birth } \\
\text { Defects } \\
\text { (a) }\end{array}$ & $\begin{array}{c}\text { Percent of Patients with } \\
\text { Birth Defects per Region } \\
\text { among Total Number of } \\
\text { Patients with Birth Defects } \\
\text { (a/n*100 where n = 12,827) }\end{array}$ \\
\hline Cordillera Administrative & 54 & $0.42 \%$ \\
Region (CAR) & 6,594 & $51.41 \%$ \\
National Capital Region (NCR) & 194 & $1.51 \%$ \\
Ilocos Region (I) & 97 & $0.76 \%$ \\
Cagayan Valley (II) & 1,407 & $10.97 \%$ \\
Central Luzon (III) & 3,339 & $26.03 \%$ \\
CALABARZON (IV-A) & 210 & $1.64 \%$ \\
MIMAROPA (IV-B) & 250 & $1.95 \%$ \\
Bicol (V) & 185 & $1.44 \%$ \\
Western Visayas (VI) & 38 & $0.30 \%$ \\
Central Visayas (VII) & 99 & $0.77 \%$ \\
Eastern Visayas (VIII) & 19 & $0.15 \%$ \\
Zamboanga Peninsula (IX) & 42 & $0.33 \%$ \\
Northern Mindanao (X) & 6 & $0.05 \%$ \\
Davao (XI) & 27 & $0.21 \%$ \\
SOCCSKSARGEN (XII) & 24 & $0.19 \%$ \\
Caraga (XIII) & & $0.05 \%$ \\
Autonomous Region of & 6 & $1.84 \%$ \\
Muslim Mindanao (ARMM) & & \\
Unspecified Region & & \\
(address incomplete) & 236 & \\
Total number of patients with & 12,827 & \\
birth defects & & \\
\hline & & \\
\hline
\end{tabular}


Table 5. Distribution of Birth Defect Cases seen at PGH OPD from 2000 to 2010 Categorized by Age Group and Organ System

\begin{tabular}{|c|c|c|c|c|c|c|c|c|c|c|c|}
\hline \multirow{3}{*}{ ICD Category } & \multicolumn{11}{|c|}{ Age Group } \\
\hline & $\begin{array}{c}<1 \\
n=5,168\end{array}$ & $\begin{array}{c}1 \text { to } 4 \\
n=3,723\end{array}$ & $\begin{array}{c}5 \text { to } 9 \\
n=1,869\end{array}$ & $\begin{array}{c}10 \text { to } 14 \\
n=885\end{array}$ & $\begin{array}{c}15 \text { to } 19 \\
n=441\end{array}$ & $\begin{array}{c}20 \text { to } 24 \\
n=235\end{array}$ & $\begin{array}{c}25 \text { to } 34 \\
n=234\end{array}$ & $\begin{array}{c}35 \text { to } 44 \\
n=97\end{array}$ & $\begin{array}{c}>44 \\
\mathrm{n}=47\end{array}$ & $\begin{array}{c}\text { Unspecified } \\
\mathbf{n}=\mathbf{1 2 8}\end{array}$ & $\begin{array}{c}\text { Total } \\
\mathrm{n}=12,827\end{array}$ \\
\hline & $\begin{array}{c}\text { Percent } \\
(\%)^{*}\end{array}$ & $\begin{array}{c}\text { Percent } \\
(\%)^{*}\end{array}$ & $\begin{array}{c}\text { Percent } \\
(\%)^{*}\end{array}$ & $\begin{array}{c}\text { Percent } \\
(\%)^{*}\end{array}$ & $\begin{array}{c}\text { Percent } \\
(\%)^{*}\end{array}$ & $\begin{array}{c}\text { Percent } \\
(\%)^{*}\end{array}$ & $\begin{array}{c}\text { Percent } \\
(\%)^{*}\end{array}$ & $\begin{array}{c}\text { Percent } \\
(\%)^{*}\end{array}$ & $\begin{array}{l}\text { Percent } \\
(\%)^{*}\end{array}$ & $\begin{array}{c}\text { Percent } \\
(\%)^{*}\end{array}$ & $\begin{array}{c}\text { Percent } \\
(\%)^{*}\end{array}$ \\
\hline Digestive System & 28.47 & 20.08 & 17.17 & 13.30 & 26.40 & 18.18 & 12.34 & 9.28 & 4.44 & 23.47 & 22.51 \\
\hline Genital Organs & 9.17 & 24.77 & 22.42 & 29.09 & 16.78 & 33.47 & 38.30 & 31.96 & 51.11 & 2.04 & 18.53 \\
\hline Cardiovascular System & 13.53 & 15.17 & 18.78 & 20.86 & 21.48 & 16.12 & 17.45 & 18.56 & 13.33 & 8.16 & 15.67 \\
\hline Nervous System & 18.82 & 10.45 & 6.28 & 5.30 & 3.13 & 2.07 & 2.55 & 3.09 & 0.00 & 7.14 & 12.19 \\
\hline Eye, ear, face and neck & 4.30 & 7.75 & 11.48 & 8.46 & 13.65 & 12.40 & 10.64 & 9.28 & 8.89 & 24.49 & 7.44 \\
\hline Musculoskeletal System & 5.08 & 4.64 & 4.02 & 4.96 & 3.80 & 3.72 & 3.83 & 2.06 & 4.44 & 1.02 & 4.64 \\
\hline Respiratory System & 0.15 & 0.29 & 0.70 & 0.45 & 0.67 & 0.00 & 0.00 & 0.00 & 2.22 & 0.00 & 0.31 \\
\hline Urinary System & 0.12 & 0.21 & 0.32 & 0.11 & 0.45 & 0.41 & 0.85 & 4.12 & 4.44 & 0.00 & 0.25 \\
\hline Other Anomalies & 0.27 & 1.29 & 2.47 & 2.25 & 1.57 & 4.96 & 3.40 & 11.34 & 11.11 & 11.22 & 1.42 \\
\hline $\begin{array}{l}\text { Multiple Congenital } \\
\text { Anomalies }\end{array}$ & 11.83 & 8.26 & 7.03 & 6.43 & 5.59 & 2.48 & 3.83 & 5.15 & 2.22 & 17.35 & 9.14 \\
\hline $\begin{array}{l}\text { Chromosomal } \\
\text { Abnormalities }\end{array}$ & 6.60 & 5.57 & 8.15 & 5.75 & 3.13 & 0.83 & 2.55 & 2.06 & 0.00 & 6.12 & 6.10 \\
\hline Recognizable Syndromes & 1.41 & 1.31 & 1.45 & 2.82 & 2.01 & 2.48 & 3.83 & 3.09 & 2.22 & 29.59 & 1.80 \\
\hline
\end{tabular}

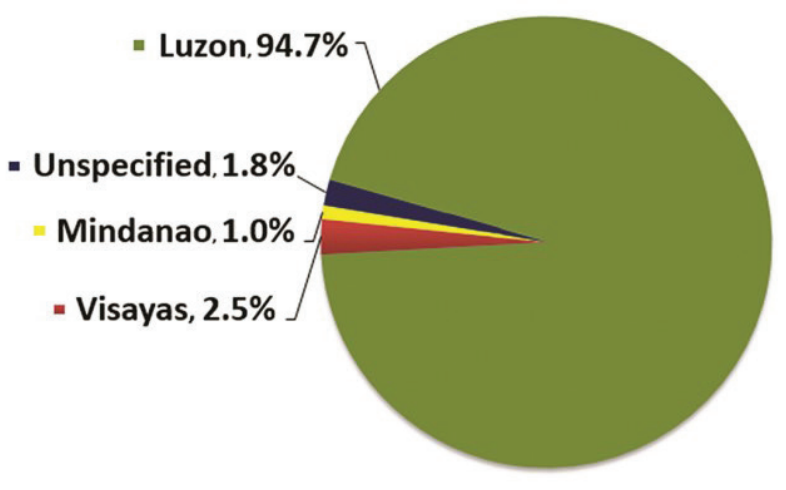

ELzon Visayas Mindanao $\quad$ Unspecified

Figure 1. Percentage distribution of patients with birth defects at the Outpatient Department of the Philippine General Hospital from 2000-2010 according to place of residence by island groups.

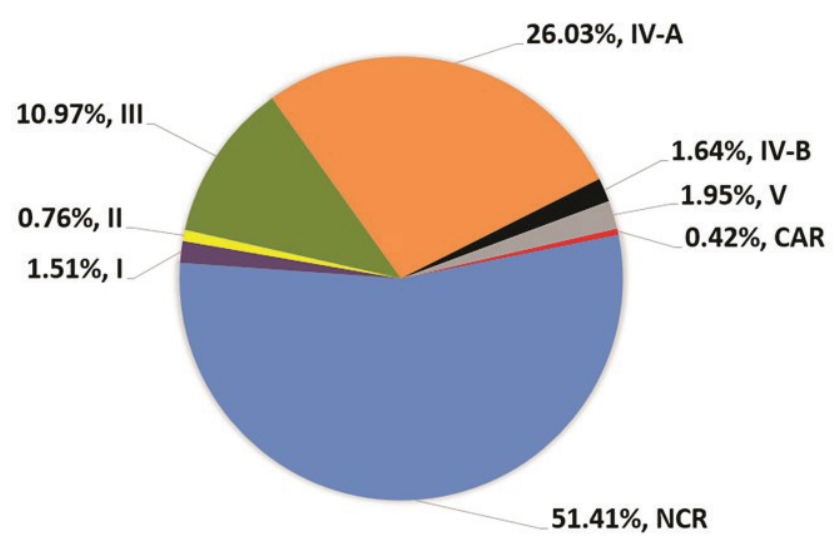

Figure 2. Percentage distribution of patients with birth defects at the Outpatient Department of the Philippine General Hospital from 2000-2010 according to regional resident in Luzon.

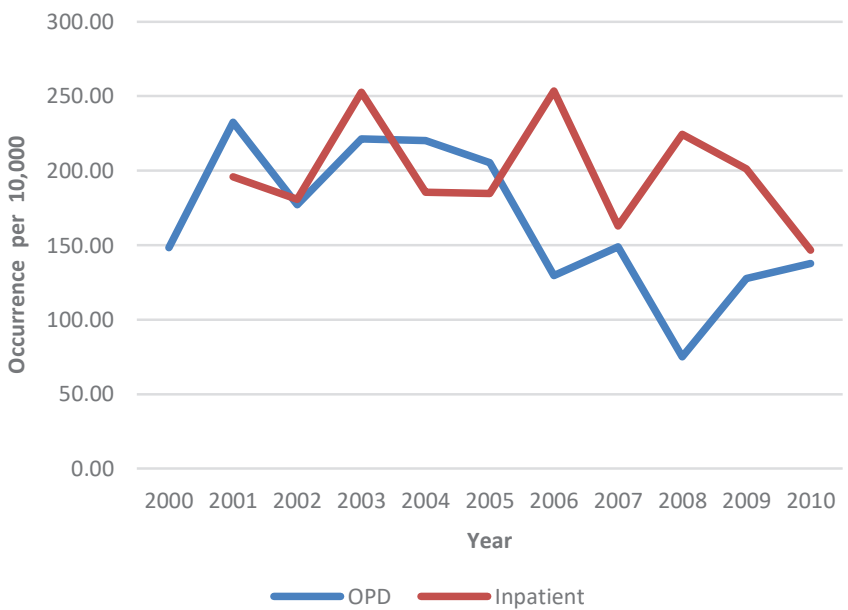

Figure 3. Patients with Birth Defects per 10, 000 OPD patient vs inpatients ${ }^{4}$ at PGH from 2000 to 2010.

\section{Discussion}

Congenital malformations occur in $2-3 \%$ of all pregnancies caused by several contributing factors such as single-gene mutations (20\%), chromosomal abnormalities $(25 \%)$, environmental teratogen $(5 \%)$, multifactorial $(40 \%)$, and copy number variants $(10 \%) .8,9$ In countries where prenatal diagnosis (ultrasound, chorionic villus sampling or amniocentesis, etc) is routinely offered to pregnant women, detection of birth defects or congenital anomalies is made prior to the birth of the baby. This allows psychological preparation of the parents as well as referral to a tertiary hospital for anticipatory care of the baby with serious birth defects. In the Philippines, the great majority of the babies are diagnosed only at birth. In the 2006 March of Dimes Global Report on Birth Defects, the Philippines had an estimated prevalence of 52.9 birth defects per 1,000 live births or 1 birth defect per 19 deliveries. ${ }^{1}$ With this estimate, we expect 105,263 birth defects (all types) every year with 2 million babies a year. 
The reported prevalence of birth defects in this study was $1.59 \%$, which was lower than most reported prevalence data in other birth defects registry reports. ${ }^{10,11}$ This can be attributed to the bigger denominator with the inclusion of all age groups in this study. Most prevalence studies include only the perinatal and neonatal period. The inclusion of all age groups was intentional to capture the burden of birth defects at all age groups.

The prevalence in this study is lower than the prevalence of birth defects among PGH inpatients of $2 \%$ during the same time period. ${ }^{4}$ The comparison with the PGH inpatients data is an attempt to compare the cases more commonly seen among outpatients vs cases more commonly seen only among inpatients. In both outpatients and inpatients, majority of the patients had isolated birth defects. Birth defects associated in multi-malformed cases ranked second in both studies.

Among outpatients, the less serious cases of birth defects will not need admission and may need only outpatient care. Diagnoses which were more commonly seen among outpatients rather than inpatients were third (oculomotor) nerve palsy, esotropia, exotropia, amblyopia ex anopsia, blindness, unspecified visual loss, congenital nystagmus, congenital hydrocele, and inguinal hernia. In contrast to the PGH inpatient study, ${ }^{4}$ there was no reported case of anencephaly among the reported neutral tube defects in this study since patients with anencephaly usually succumb to death within the first few hours to days of life. Among inpatients, the fewer occurrences of chromosomal abnormalities and multiple congenital anomalies in the older age groups reflect the shorter life span of patients with such conditions. Only recognizable syndromes compatible with life reach the older age groups.

There is the possibility on the overlap of cases between the outpatients and the inpatients since patients with surgically correctible birth defects will eventually be admitted. There is also the possibility that the surgery was performed in other hospitals and thus will not be reflected in the PGH inpatient data. There was no attempt to analyze the overlap of cases.

Most birth defects were observed in the under- 5 age group with a combined percentage of $69.3 \%$ from both the < 1 age group and the 1 to 4 age group. This is a major finding since the under- 5 mortality rate in the Philippines remains high at 30 per 1,000 live births. ${ }^{12-14}$ Birth defects remain to be a leading cause of infant mortality in the Philippines in the past six decades. ${ }^{2}$ The absence of a national birth defect surveillance could be the reason for the absence of focused programs that specifically address its reduction. There is no formal detailed study on the real burden of birth defects or congenital anomalies in the national data on infant mortality where congenital anomalies have consistently been in the top 5 .
Just like the March of Dimes Global Report on Birth Defects where congenital heart defects were the most common form of birth defects occurring in 4-8 per 1,000 live births, ${ }^{1}$ this study revealed that cardiovascular system anomalies were the most common.

Digestive system anomalies and nervous system anomalies were included in the top birth defects in Iran and Japan as reported in the 2011 Annual Report of the International Clearinghouse for Birth Defects and Surveillance and Research (ICBDSR). ${ }^{15}$ For the years 20072011, cleft lip with or without cleft palate occurred in 26.01 and 21.67 per 10,000 in Iran and Japan, respectively. Hydrocephalus on the other hand is more common in Iran with a prevalence of 11.38 per 10,000 compared to Japan's 7.82 per $10,000 .{ }^{15}$ Although trends seen in this study were similar, it was difficult to make straight comparisons since the patients in this study included all age groups from various outpatient clinics at PGH whereas those of the ICBDSR only included live births, stillbirths and termination of pregnancies.

In both inpatients and outpatients, congenital rubella syndrome (CRS) was prominently observed. There were 110 patients with congenital rubella syndrome (CRS) occurring at 1.37 per 10,000 outpatients in this study whereas 39 patients with CRS were reported in the PGH inpatient study at 0.89 per 10,000 admissions. ${ }^{4}$ This study presented an even higher number as compared to the study by Agnas et al which reported the occurrence of 58 cases of CRS for a period of 10 years $\left(1993\right.$ - 2002) at PGH. ${ }^{16}$ The significance of this data is the fact that it is preventable. Rubella, one of the vaccine-preventable viral conditions, can potentially cause birth defects to the unborn fetus if the mother becomes infected during the first 16 weeks of pregnancy. ${ }^{1}$ About $25 \%$ of mothers who had rubella during the first trimester of pregnancy will have babies affected with CRS. Birth defects in CRS include blindness, hearing impairment, heart defects, and intellectual disability. ${ }^{1}$ With the wide availability of MMR vaccine in the market, national efforts to improve MMR vaccination among Filipinos need to be undertaken and strengthened.

Similarly, there is an opportunity to reduce the burden of neural tube defects (NTD) with anencephaly at the end of the spectrum. Studies have shown that adequate intake of folic acid results in a range of $37 \%$ to $92 \%$ reduction of NTD occurrence. ${ }^{17-20}$ Thus, it is recommended that women of childbearing age should supplement with $0.4 \mathrm{mg}$ (400ug) of folic acid daily, two months prior to conception and until the $12^{\text {th }}$ week of gestation. ${ }^{21-24}$ In the Philippines, $16 \%$ of pregnancies are unplanned and $20 \%$ are mistimed. ${ }^{25}$

The hospital received referrals from other regions in as far as the Mindanao areas. The reason for the referrals could be the need for specialized services which are not available in the hospitals in the said areas. One of these specialized services is a formal genetic assessment for proper diagnosis 
and management. Currently, there are only ten geneticists who can serve the 100 million Filipinos ${ }^{12,13}$ and the majority are practicing in the NCR. While training of additional geneticists is a challenge, efforts have been made to make genetics services more available for Filipinos despite geographical adversities. One major effort is the Telegenetics Referral system, which has been piloted by the Institute of Human Genetics-National Institutes of Health, University of the Philippines Manila in collaboration with the DOH. The aim of this program is to make the services of a genetics team available even in remote areas through email and/or teleconference video calls. Another program to address the lack of genetic services is the offering of the Master of Science in Genetic Counseling by the Department of Pediatrics, College of Medicine, University of the Philippines Manila. ${ }^{26}$ It aims to train genetic counselors who can be fielded to the different regions in the country.

The PGH is probably the biggest government hospital with the widest complement of specialized services that can help patients with birth defects. Its residency and fellowship programs have graduated specialists and subspecialists that now man the different hospitals in the country. It is the only hospital with a genetics clinic among its OPD clinics. The PGH, together with National Institutes of Health, provides comprehensive genetic services to its patients through the geneticists, genetic counselors, genetic nurses of the Section of Genetics, PGH Department of Pediatrics and the Institute of Human Genetics, National Institutes of Health.

The data generated by this study may be limited being collected only in one hospital but the number of patients coming from all regions in the country makes it an excellent surrogate of the Philippine scenario. Both studies, the inpatients and the outpatients, can be the basis of programs that can reduce the burden of birth defects through: 1) better preparation of pregnancies (immunization programs, folic acid supplementation, etc); 2) early diagnosis of birth defects for anticipatory care of the baby in a well-equipped facility (improved capability of physicians through training of specialists and subspecialists in designated regional and provincial hospitals, upgrading of designated regional and provincial hospitals, etc); 3) development of a comprehensive program (both diagnosis, short term and long term management) for patients with birth defects; and 4) the integration of the affected children into society so that that can be productive adults.

The forged partnership between government (Department of Health and the Department of the Interior and Local Government) and academe (National Institutes of Health, University of the Philippines Manila) can develop programs that will redound to the reduction of morbidity and mortality among newborns, children and adults with birth defects or congenital anomalies.

\section{Conclusions}

Birth defects occurred in $1.59 \%$ of new patients at the OPD of PGH from 2000 to 2010. The most common defects seen were possibly surgically correctable, reflecting the nature of PGH being a tertiary referral center. Majority of patients affected were in the under- 5 population, which suggests that birth defects are possibly a contributing factor to morbidity and/or mortality in the country's under-5 population.

The results of this study complement the previously published inpatient data. Both studies similarly show that the most common birth defects were cardiovascular, digestive, genital organ and nervous system anomalies. The top 5 anomalies in this report were: congenital malformations of cardiac septa, other congenital malformations not elsewhere classified, cleft palate with cleft lip, congenital hydrocoele, and congenital hydrocephalus.

The study reinforces the importance of a birth defects surveillance to develop policies on strategies that will reduce the burden of morbidity and mortality secondary to preventable birth defects. Excellent examples are congenital rubella syndrome that can be aborted by a successful immunization program and the folic acid supplementation and fortification that can dramatically reduce neural tube defects. The birth defects surveillance will also generate the data that will support strengthening the regional hospitals with a better complement of specialists and capability for both medical and surgical management of the patients.

\section{Acknowledgments}

The authors thank the Philippine General Hospital Records Section for their kind support. Appreciation is also given to Ms. Angela Villa, Ms. Josha Reanzares, Ms. May Anne Mendoza, Ms. Lorraine Abegail Costales, Ms. Jerianne Santiago, Dr. Kathryn Ty, and Dr. Ma-Am Joy Tumulak for their help with review of records, encoding of data and safekeeping of the database. Also, special thanks to Ms. Teresita Gaspar and Ms. Lee Ann Hablado for their efforts in the retrieval of records.

The authors also thank the Institute of Human Genetics-National Institutes of Health, University of the Philippines Manila for support of salaries of the research assistants.

\section{Statement of Authorship}

All authors have approved the final version submitted.

\section{Author Disclosure}

All authors declared no conflict of interest.

\section{Funding Source}

This study was funded by the Institute of Human Genetics. 


\section{References}

1. Christianson A, Howson CP, Modell B. March of Dimes Global Report on Birth Defects: The Hidden Toll of Dying and Disabled Children [Online]. 2006 [cited 2016 Mar]. Available from http://www. marchofdimes.com/materials/global-report-on-birth-defects-the-hiddentoll-of-dying-and-disabled-children-full-report.pdf.

2. Department of Health. Top 10 Causes of Infant Mortality [Online]. 2010 [cited 2017 Sep]. Available from http://www.doh.gov.ph.

3. Padilla CD, Cutiongco EM, Sia JM. Birth defects ascertainment in the Philippines. Southeast Asian J Trop Med Public Health. 2003;34 Suppl 3:239-43.

4. Padilla CD, Dion-Berboso AG, Abadingo ME, et al. Occurrence of Birth Defects at the Philippine General Hospital: 2001-2010. Acta Med Philipp. 2011; 45(4):20-9.

5. WHO/CDC/ICBDSR. Birth defects surveillance: a manual for programme managers. Geneva: World Health Organization [Online]. 2014 [cited 2017 Sep]. Available from https://www.cdc.gov/ncbddd/ birthdefectscount/documents/bd-surveillance-manual.pdf.

6. National Institute of Child Health and Development. What are the types of birth defects [Online]. 2017 [cited 2017 Sep]. Available from https://www.nichd.nih.gov/health/topics/birthdefects/conditioninfo/pag es/types.aspx

7. Jones KL, Jones MC, Campo MD, Smith, DW. Smith's recognizable patterns of human malformation, 7th ed. Philadelphia, Pa.: Elsevier Saunders.; 2013. pp. 1-2.

8. Harper PS. Practical Genetic Counseling, 7th ed. London: Hodder Arnold, an imprint of Hodder Education; 2010. p. 91.

9. Nussbaum RL, McInnes RR, Willard HF, Hamosh A. Genetics in Medicine, 8th ed. Philadelphia: Saunders Elsevier; 2016. p.285.

10. Kim MA, Yee NH, Choi JS, Choi JY, and Seo K. Prevalence of birth defects in Korean livebirths, 2005-2006. J Korean Med Sci. 2012; 27(10):1233-40.

11. Egbe AC. Birth defects in the newborn population: race and ethnicity. Pediatr Neonatol. 2015; 56(3):183-8.

12. Philippine Statistics Authority. Death among Children Under Five Years of Age Continues to Decline. [Online]. 2012 [cited 2017 Sep]. Available from https://psa.gov.ph/content/death-among-children-under-five-yearsage-continues-decline-results-2011-family-health.

13. Philippine Statistics Authority. Population Projections [Online]. 2016 [cited 2016 Mar]. Available from http://www.nscb.gov.ph/ secstat/d_popnProj.asp.

Appendix A: List of minor defects excluded from this study

- frontal bossing

- epicanthal folds

- proptosis

- hypertelorism

- hypotelorism

- low set ears

- deformation of ears

- folded superior helix

- prominent ears/ antihelix

- flat nasal bridge

- upturned nose

- $\quad$ shallow nasolabial fold

- long philtrum

- maxillary hypoplasia

- widely spaced teeth

- macroglossia
14. UN Inter-Agency Group for Child Mortality Estimation (UNICEF, WHO, World Bank, UN DESA Population Division). Mortality rate, under-5 (per 1, 000 live births) [Online]. 2016 [cited 2016 Mar]. Available from http://data.worldbank.org/indicator/SH.DYN.MORT.

15. International Clearinghouse for Birth Defects Surveillance and Research. Annual Report 2011 with data for 2009 [Online]. 2011 [cited 2016 Mar]. Available from http://www.icbdsr.org/filebank/documents/ ar2005/Report2011.pdf.

16. Agnas CL. The Analysis of Clinical and Social Profile of Congenital Rubella Syndrome seen among UP-PGH Patients from the Years 1993 2002 (A 10-year Prevalence Review). PIDSP Journal. 2005; 9(2):51-56.

17. Wang H, De Steur H, Chen G, et al. Effectiveness of folic acid fortified flour for prevention of neural tube defects in a high-risk region. Nutrients. 2016; 8(3):152.

18. Liu J, Jin L, Meng Q, et al. Changes in folic acid supplementation behaviour among women of reproductive age after the implementation of a massive supplementation programme in China. Public Health Nutr. 2015; 18(4):582-8.

19. Ren AG. Prevention of neural tube defects with folic acid: The Chinese experience. World J Clin Pediatr. 2015; 4(3):41-4

20. Blencowe H, Cousens S, Modell B, Lawn J. Folic acid to reduce neonata mortality from neural tube disorders. Int J Epidemiol. 2010; 39 Suppl 1:1110-21.

21. Recommendations. Atlanta (GA): Division of Birth Defects, National Center on Birth Defects and Developmental Disabilities, Centers for Disease Control and Prevention [Online]. updated 2016 Dec [cited 2017 Sep]. Available from https://www.cdc.gov/ncbddd/folicacid/ recommendations.html

22. Folic acid. White Plains (NY): March of dimes [Online]. [cited 2017 Sep] Available from http://www.marchofdimes.org/pregnancy/folic-acid.aspx

23. Chitayat D, Matsui D, Amitai Y, et al. Folic acid supplementation for pregnant women and those planning pregnancy: 2015 update. J Clin Pharmacol. 2016;56(2): 170-5.

24. World Health Organization. Prevention of neural tube defects Standards for Maternal and Neonatal Care. 2006.

25. One in three births in the Philippines is unplanned. Manila: Philippine Statistics Authority [Online]. [cited 2017 Aug]. Available from https://psa.gov.ph/article/one-three-births-philippines-unplanned

26. Laurino MY, Padilla CD, Alcausin MB, Silao CL, de la Paz EMC. A Master of Science in Genetic Counseling Program in the Philippines. Acta Med Philipp. 2011; 45(4):7-9. 
Appendix B: Complete list of birth defects and their respective ICD codes

\begin{tabular}{|c|c|c|c|c|c|c|c|}
\hline & ICD Code & $\begin{array}{c}\text { Isolated } \\
\text { and } \\
\text { Sequence }\end{array}$ & $\begin{array}{c}\text { Associated } \\
\text { defect in } \\
\text { MMC }\end{array}$ & $\begin{array}{c}\text { Part of } \\
\text { recognizable } \\
\text { syndrome }\end{array}$ & $\begin{array}{c}\text { Part of } \\
\text { chromosomal } \\
\text { syndromes }\end{array}$ & Total & $\begin{array}{c}\text { Occurrence } \\
\text { per } 10,000 \\
\text { patients }\end{array}$ \\
\hline \multicolumn{2}{|c|}{ Nervous system } & 1,564 & 283 & 19 & 9 & 1,875 & 23.31 \\
\hline Q00 & Anencephaly and similar malformations & 0 & 0 & 0 & 0 & 0 & 0.00 \\
\hline Q01 & Encephalocele & 315 & 42 & 0 & 0 & 357 & 4.44 \\
\hline Q02 & Microcephaly & 198 & 118 & 15 & 7 & 338 & 4.20 \\
\hline Q03 & Congenital hydrocephalus & 741 & 70 & 3 & 2 & 816 & 10.14 \\
\hline Q04 & Other congenital malformations of the brain & 47 & 25 & 0 & 0 & 72 & 0.90 \\
\hline Q05 & Spina bifida & 226 & 25 & 1 & 0 & 252 & 3.13 \\
\hline Q06 & Other congenital malformations of the spinal cord & 4 & 1 & 0 & 0 & 5 & 0.06 \\
\hline Q07 & Other congenital malformations of the nervous system & 33 & 2 & 0 & 0 & 35 & 0.44 \\
\hline \multicolumn{2}{|c|}{ Eye Anomalies } & 597 & 207 & 73 & 20 & 897 & 11.15 \\
\hline Q10 & Congenital malformations of eyelid, lacrimal apparatus and orbit & 101 & 25 & 4 & 8 & 138 & 1.72 \\
\hline Q11 & Anophthalmos, microphthalmos and macrophthalmos & 37 & 57 & 2 & 0 & 96 & 1.19 \\
\hline Q12 & Congenital lens malformations & 288 & 56 & 64 & 6 & 414 & 5.15 \\
\hline Q13 & Congenital malformations of anterior segment of eye & 20 & 18 & 2 & 0 & 40 & 0.50 \\
\hline Q14 & Congenital malformations of posterior segment of eye & 2 & 2 & 0 & 0 & 4 & 0.05 \\
\hline Q15 & Other congenital malformations of eye & 41 & 15 & 1 & 1 & 58 & 0.72 \\
\hline H49.0 & Third (oculomotor) nerve palsy & 1 & 0 & 0 & 0 & 1 & 0.01 \\
\hline H50.0 & Esotropia & 96 & 30 & 0 & 5 & 131 & 1.63 \\
\hline H50.1 & Exotropia & 7 & 0 & 0 & 0 & 7 & 0.09 \\
\hline H53.0 & Amblyopia ex anopsia & 0 & 1 & 0 & 0 & 1 & 0.01 \\
\hline H54.42 & Blindness, left eye, normal vision right eye & 1 & 0 & 0 & 0 & 1 & 0.01 \\
\hline H54.7 & Unspecified Visual Loss & 0 & 2 & 0 & 0 & 2 & 0.02 \\
\hline H55.01 & Congenital nystagmus & 3 & 1 & 0 & 0 & 4 & 0.05 \\
\hline \multicolumn{2}{|c|}{ Ear Anomalies, Face and Neck } & 357 & 87 & 34 & 7 & 485 & 6.03 \\
\hline Q16 & Congenital malformations of ear causing impairment of hearing & 263 & 27 & 29 & 4 & 323 & 4.02 \\
\hline Q17 & Other congenital malformations of ear & 61 & 35 & 2 & 1 & 99 & 1.23 \\
\hline Q18 & Other congenital malformations of face and neck & 33 & 25 & 3 & 2 & 63 & 0.78 \\
\hline \multicolumn{2}{|c|}{ Cardiovascular System Anomalies } & 2,010 & 985 & 82 & 250 & 3,327 & 41.36 \\
\hline Q20 & Congenital malformations of cardiac chambers and connections & 34 & 90 & 0 & 1 & 125 & 1.55 \\
\hline Q21 & Congenital malformations of cardiac septa & 1,324 & 447 & 28 & 176 & 1,975 & 24.55 \\
\hline Q22 & Congenital malformations of pulmonary and tricuspid valves & 87 & 134 & 8 & 3 & 232 & 2.88 \\
\hline Q23 & Congenital malformations of aortic and mitral valves & 11 & 7 & 4 & 0 & 22 & 0.27 \\
\hline Q24 & Other congenital malformations of heart & 61 & 40 & 2 & 2 & 105 & 1.31 \\
\hline Q25 & Congenital malformations of great arteries & 443 & 263 & 40 & 68 & 814 & 10.12 \\
\hline Q26 & Congenital malformations of great veins & 12 & 3 & 0 & 0 & 15 & 0.19 \\
\hline Q27 & Other congenital malformations of peripheral vascular system & 1 & 1 & 0 & 0 & 2 & 0.02 \\
\hline Q28 & Other congenital malformations of circulatory system & 37 & 0 & 0 & 0 & 37 & 0.46 \\
\hline \multicolumn{2}{|c|}{ Respiratory System Anomalies } & 40 & 13 & 1 & 1 & 55 & 0.68 \\
\hline Q30 & Congenital malformations of nose & 6 & 12 & 1 & 0 & 19 & 0.24 \\
\hline Q31 & Congenital malformations of larynx & 26 & 0 & 0 & 1 & 27 & 0.34 \\
\hline Q32 & Congenital malformations of trachea and bronchus & 0 & 0 & 0 & 0 & 0 & 0.00 \\
\hline Q33 & Congenital malformations of lung & 2 & 1 & 0 & 0 & 3 & 0.04 \\
\hline Q34 & Other congenital malformations of respiratory system & 6 & 0 & 0 & 0 & 6 & 0.07 \\
\hline \multicolumn{2}{|c|}{ Digestive System Anomalies } & 2,887 & 336 & 19 & 67 & 3,309 & 41.14 \\
\hline Q35 & Cleft palate & 507 & 84 & 7 & 7 & 605 & 7.52 \\
\hline Q36 & Cleft lip & 405 & 26 & 1 & 1 & 433 & 5.38 \\
\hline Q37 & Cleft palate with cleft lip & 1,036 & 111 & 1 & 5 & 1,153 & 14.33 \\
\hline Q38 & Other congenital malformations of tongue, mouth and pharynx & 3 & 16 & 3 & 0 & 22 & 0.27 \\
\hline Q39 & Congenital malformations of esophagus & 3 & 10 & 3 & 0 & 16 & 0.20 \\
\hline Q40 & Other congenital malformations of upper alimentary tract & 0 & 0 & 0 & 0 & 0 & 0.00 \\
\hline Q41 & Congenital absence, atresia and stenosis of small intestine & 2 & 1 & 0 & 1 & 4 & 0.05 \\
\hline Q42 & Congenital absence, atresia and stenosis of large intestine & 385 & 61 & 4 & 46 & 496 & 6.17 \\
\hline Q43 & Other congenital malformations of intestine & 245 & 12 & 0 & 4 & 261 & 3.24 \\
\hline Q44 & Congenital malformations of gallbladder, bile ducts and liver & 301 & 15 & 0 & 3 & 319 & 3.97 \\
\hline Q45 & Other congenital malformations of digestive system & 0 & 0 & 0 & 0 & 0 & 0.00 \\
\hline \multicolumn{2}{|c|}{ Genital Organ Anomalies } & 2,377 & 290 & 8 & 29 & 2,704 & 33.61 \\
\hline Q50 & Congenital malformations of ovaries, fallopian tubes and broad ligaments & 0 & 1 & 0 & 0 & 1 & 0.01 \\
\hline Q51 & Congenital malformations of uterus and cervix & 7 & 2 & 0 & 0 & 9 & 0.11 \\
\hline Q52 & Other congenital malformations of female genitalia & 63 & 13 & 2 & 1 & 79 & 0.98 \\
\hline Q53 & Undescended testicle & 630 & 126 & 3 & 16 & 775 & 9.63 \\
\hline Q54 & Hypospadias & 295 & 77 & 1 & 8 & 381 & 4.74 \\
\hline Q55 & Other congenital malformations of male genital organs & 0 & 19 & 0 & 0 & 19 & 0.24 \\
\hline Q56 & Indeterminate sex and pseudohermaphroditism & 11 & 30 & 1 & 3 & 45 & 0.56 \\
\hline P83.5 & Congenital hydrocoele & 1,074 & 8 & 0 & 0 & 1,082 & 13.45 \\
\hline K40 & Inguinal hernia & 297 & 14 & 1 & 1 & 313 & 3.89 \\
\hline
\end{tabular}




\begin{tabular}{|c|c|c|c|c|c|c|c|}
\hline \multicolumn{2}{|c|}{ Urinary System Anomalies } & \multirow{2}{*}{\begin{tabular}{r|r}
32 \\
2
\end{tabular}} & \multirow{2}{*}{$\begin{array}{r}18 \\
3\end{array}$} & \multirow{2}{*}{$\begin{array}{ll}4 \\
1\end{array}$} & \multirow{2}{*}{$\frac{2}{0}$} & \multirow{2}{*}{$\begin{array}{r}56 \\
6\end{array}$} & \multirow{2}{*}{$\begin{array}{ll}0.70 \\
0.07\end{array}$} \\
\hline Q60 & Renal agenesis and other reduction defects of kidney & & & & & & \\
\hline Q61 & Cystic kidney disease & 14 & 2 & 0 & 0 & 16 & 0.20 \\
\hline Q62 & $\begin{array}{l}\text { Congenital obstructive defects of renal pelvis and congenital } \\
\text { malformations of ureter }\end{array}$ & 6 & 3 & 1 & 1 & 11 & 0.14 \\
\hline Q63 & Other congenital malformations of kidney & 3 & 3 & 2 & 1 & 9 & 0.11 \\
\hline Q64 & Other congenital malformations of urinary system & 7 & 7 & 0 & 0 & 14 & 0.17 \\
\hline \multicolumn{2}{|c|}{ Musculoskeletal System Anomalies } & 595 & 553 & 60 & 35 & 1,243 & 15.45 \\
\hline Q65 & Congenital deformities of hip & 6 & 9 & 2 & 0 & 17 & 0.21 \\
\hline Q66 & Congenital deformities of feet & 301 & 128 & 4 & 14 & 447 & 5.56 \\
\hline Q67 & Congenital musculoskeletal deformities of head, face, spine and chest & 14 & 56 & 5 & 2 & 77 & 0.96 \\
\hline Q68 & Other congenital musculoskeletal deformities & 3 & 13 & 0 & 0 & 16 & 0.20 \\
\hline Q69 & Polydactyly & 37 & 39 & 3 & 3 & 82 & 1.02 \\
\hline Q70 & Syndactyly & 36 & 73 & 7 & 3 & 119 & 1.48 \\
\hline Q71 & Reduction defects of upper limb & 5 & 16 & 0 & 4 & 25 & 0.31 \\
\hline Q72 & Reduction defects of lower limb & 0 & 21 & 1 & 0 & 22 & 0.27 \\
\hline Q73 & Reduction defects of unspecified limb & 0 & 5 & 0 & 0 & 5 & 0.06 \\
\hline Q74 & Other congenital malformations of limb(s) & 26 & 95 & 14 & 7 & 142 & 1.77 \\
\hline Q75 & Other congenital malformations of skull and face bones & 78 & 42 & 1 & 1 & 122 & 1.52 \\
\hline Q76 & Congenital malformations of spine and bony thorax & 40 & 27 & 5 & 0 & 72 & 0.90 \\
\hline Q77 & Osteochondrodysplasia with growth of tubular bones and spine & 0 & 2 & 9 & 0 & 11 & 0.14 \\
\hline Q78 & Other osteochondrodysplasias & 0 & 0 & 6 & 0 & 6 & 0.07 \\
\hline Q79 & $\begin{array}{l}\text { Congenital malformations of the musculoskeletal system, } \\
\text { not elsewhere classified }\end{array}$ & 49 & 27 & 3 & 1 & 80 & 0.99 \\
\hline \multicolumn{2}{|c|}{ Others } & 182 & 1,196 & 201 & 3 & 1,582 & 19.67 \\
\hline Q80 & Congenital ichthyosis & 0 & 0 & 11 & 0 & 11 & 0.14 \\
\hline Q82 & Other congenital malformations of skin & 6 & 1 & 1 & 0 & 8 & 0.10 \\
\hline Q83 & Congenital malformations of breast & 0 & 4 & 0 & 0 & 4 & 0.05 \\
\hline Q84 & Other congenital malformations of integument & 3 & 6 & 0 & 0 & 9 & 0.11 \\
\hline Q85 & Phakomatoses, not elsewhere classified & 1 & 0 & 31 & 0 & 32 & 0.40 \\
\hline Q86 & $\begin{array}{l}\text { Congenital malformation syndromes due to known exogenous causes, } \\
\text { not elsewhere classified }\end{array}$ & 0 & 0 & 1 & 0 & 1 & 0.01 \\
\hline Q87 & $\begin{array}{l}\text { Other specified congenital malformation syndromes } \\
\text { affecting multiple systems }\end{array}$ & 15 & 4 & 45 & 3 & 67 & 0.83 \\
\hline Q89 & Other congenital malformations, not elsewhere classified & 157 & 1,181 & 2 & 0 & 1,340 & 16.66 \\
\hline P35 & Congenital rubella syndrome & 0 & 0 & 110 & 0 & 110 & 1.37 \\
\hline \multicolumn{2}{|c|}{ Chromosomal abnormalities } & 0 & 0 & 0 & 783 & 783 & 9.73 \\
\hline Q90 & Down syndrome & 0 & 0 & 0 & 758 & 758 & 9.42 \\
\hline Q91 & Edwards and Patau syndrome & 0 & 0 & 0 & 5 & 5 & 0.06 \\
\hline Q92 & $\begin{array}{l}\text { Other trisomies and partial trisomies of the autosomes, } \\
\text { not elsewhere classified }\end{array}$ & 0 & 0 & 0 & 0 & 0 & 0.00 \\
\hline Q93 & $\begin{array}{l}\text { Monosomies and deletions from the autosomes, } \\
\text { not elsewhere classified }\end{array}$ & 0 & 0 & 0 & 4 & 4 & 0.05 \\
\hline Q96 & Turner syndrome & 0 & 0 & 0 & 12 & 12 & 0.15 \\
\hline Q97 & $\begin{array}{l}\text { Other sex chromosome abnormalities, female phenotype, } \\
\text { not elsewhere classified }\end{array}$ & 0 & 0 & 0 & 0 & 0 & 0.00 \\
\hline Q98 & $\begin{array}{l}\text { Other sex chromosome abnormalities, male phenotype, } \\
\text { not elsewhere classified }\end{array}$ & 0 & 0 & 0 & 1 & 1 & 0.01 \\
\hline Q99 & Other chromosomal abnormalities, not elsewhere classified & 0 & 0 & 0 & 3 & 3 & 0.04 \\
\hline \multicolumn{2}{|c|}{ TOTAL DEFECTS } & 10,641 & 3,968 & 501 & 1,206 & 16,316 & \\
\hline \multicolumn{2}{|c|}{ TOTAL CASES } & 10,641 & 1,172 & 231 & 783 & 12,827 & \\
\hline
\end{tabular}

